\title{
TESTING GENERATIVE THINKING AMONG SWAZI CHILDREN
}

\author{
T.D. MUSHORIWA, J. SIBANDA AND H. Z. NKAMBULE \\ (Received 24, April 2008; Revision Accepted 3, November 2008) \\ ABSTRACT
}

This study tested and compared the generative thinking of second graders (7-8year olds) and fifth graders (10-11'year olds) as a means to assess how generative thinking develops among children. Results from this study were compared with results obtained by Mushoriwa (2003) in a similar study in Zimbabwe in order to establish if the development of generative thinking follows a similar pattern in different environments. Data were sourced from 40 second-graders and 40 fifth graders randomly selected from primary schools in Manzini region. The survey research design was used, with interviews employed to collect the data. Crosstabs and a two-sample t-test were used to analyse the data. The study found no significant differences in generative thinking between second and fifth graders in the Swazi sample. In the comparative analyses, while significant differences in eye placements were observed between second grade pupils in Swaziland and second grade pupils in Zimbabwe, no significant differences in eye placements were observed between fifth grade pupils in Swaziland and fifth grade pupils in Zimbabwe. As for reasons/explanations for eye placements, significant differences between Swazi and Zimbabwean children were noted at both second grade and fifth grade levels. The study recommended the use by teachers, of pedagogy that is promotive of generative thinking as well as the need for further research in the area focusing on environmental factors influencing the nature and developmental pattern of generative thinking.

KEY WORDS: Generative thinking, Developmental patterns, Hypothetical third eye, Environmental factors.

\section{INTRODUCTION}

This study sought to establish the extent and developmental patterns of generative thinking among Swazi children aged between 7 and 8 years (second graders) and between 10 and 11 years (fifth graders). [The results from this study were compared with results from a similar study by Mushoriwa (2003) on Zimbabwean pupils of the same age and grade levels.] Mushoriwa (2003) found the foundational nature of generative thinking in the development of other cognitive skills such as image formation, story production and detection of relationships as justification for the investment of time and effort in its study. Generative thinking is a field of study relatively in its infancy in Africa and the rest of the world; so the rationale for its study becomes even thinking would provide insights upon which intervention measures for the promotion of generative thought would rest. A knowledge of the developmental patterns of generative thought would help classroom practitioners determine the thought patterns learners are capable of at particular stages of their learning.

The dynamic nature of our world requires, not greater exercise of our routine traditional patterns of thinking, but rather the employment of generative, explorative, productive thinking. It is this type of thinking that should be identified, activated and nurtured in pupils at tender ages. The present study confines itself to the identification aspect.

A clear conception of the concept of generative thinking is pertinent to an greater. A study of the extent of generative

T. D. Mushoriwa, Educational Foundations \& Management, University of Swaziland

J. Sibanda, Department of Primary Education, University of Swaziland

H. Z. Nkambule, Statistics and Demography, University of Swaziland 
Understanding of this study. A conceptual explanation of generative thinking is given as follows:

Generative thinking: A conceptual framework DeBono (1970) identified three thinking aspects; namely, what is, what may be and what can be. He laments education's preoccupation and obsession with the first, underestimating the second and almost totally disregarding the third despite the fact that the future seems to depend on it entirely. The first represents what Tidona (2004) called simple thinking which is slow and ineffective in producing new ideas. The second represents critical thinking which depends on what already exists. The third level represents generative thinking, which is productive and creative. Generative thinking transcends literacy and numeracy into the realm of operacy. The thinker goes beyond concrete experiences to the world of possibilities which are not current realities. Generative thinking involves the production of new and original solutions to problems and encapsulates novelty and utility (Mushoriwa, 2003).

The twin attributes of novelty and utility which characterise generative thinking are significant in the present study whose focus was on pupils placing a hypothetical third eye on a part of the body (novelty) where it would be most useful (utility). Novelty was made manifest in the placement of the third eye out of the usual location of eyes in the face region and utility involved the placement of the third eye on the back of the head to have an all-round view.

In order to contextualise the study, related literature was reviewed. The researchers, however, acknowledge paucity of literature given that attempts to establish the extent of generative thinking among children are relatively new and few.

\section{LITERATURE REVIEW}

Generative thinking has the capacity to spot links which are not apparent as well as draw conclusions from premises not seen (Tidona, 2004). This contrasts sharply with simple thinking which reflects and registers things as they are and observes reality in its present and original form. Siegler (1996) sees the varied nature of pupils' thinking capabilities in given tasks as translating to their diversity in generative thinking capacities.

The study of generative thinking among children by Ward (1994) and Stokes (1999) reveals that generative thinking is a gradual developmental process which develops in relation to pupils' age, Intelligence Quotient (I. Q), type of task, nutrition, family and socio-economic influences. The present study kept the task type variable constant by using the same task of the placement of a hypothetical third eye for all the subjects. This enabled comparisons on the influence of age/grade level on pupils' generative thinking.

From his review of Ward's (1994) studies on college students' generative thinking, Mushoriwa (2003) concludes that age is not the sole determinant of generative thinking. The college students in question had drawn earth-like animals when they were asked to draw animals that might be found in other planets. This study demonstrated that the students failed to go beyond what they know-indicating lack of generative thinking as adults.

Generative thinking is worth studying because it can be improved upon. This type of thinking can be activated through use of novel problems the problem solver has not encountered before and for which he/she cannot produce a known solution (Mayer, 1989). The present study's use of the third eye provided that novel situation which called for generative thought. For Stokes (1999), tasks have to be deliberately designed to develop generative thinking. Harrington (1975) finds the provision of specific instructions as an important aid to generative thinking. That is why this study's task and instructions were made so simple and clear to ensure that the subjects knew exactly what was expected of them.

Hamachek (1977) sees the essence of generative, divergent thinking as originality rather than orderliness and routinisation of tasks. Beetlestone (1998) sees originality as that strand of generative thinking which allows for the making of unusual and novel connections. The generation of alternative perspectives without regard for pre-defined standardised formats for problem solving is also a measure of generative thinking (Brookfield, 1987). Fixation on past experiences diminishes insightful solutions, resists novel interpretations and becomes what Daminowski and Dalob (1995) call the antithesis of insight. Where such fixation was noted in the pupils' responses, the scoring was resultantly low. Imagination, non-conformity, difference, independence, inimitability, acceptance of ambiguity, flexibility, envisioning of alternatives, embracing of unfamiliar situations and ability to develop preferred scenarios have been identified as marks of generative thinking (Brookfield, 
1987; Pauker, 1987; and Beetlestone, 1998). The responses which manifested these qualities scored higher.

\section{METHODOLOGY}

Mushoriwa (2003) acknowledges having borrowed from Shafer's (1973) methodological procedures and instrumentation. This study does not deviate from these methodology procedures. The need to compare the present study's findings with those from Mushoriwa's (2003) study necessitates the use of a similar methodological approach.

\section{Research design}

The survey design was used for this study because it was found to be consonant with the nature of this study. The survey's usability on large samples, as is the sample for this study $(\mathrm{N}=80)$, and its ability to provide detailed descriptions, gives it an advantage (Van Dalen, 1979). The unobtrusive nature of the researcher who does nothing to the subjects except observe them or ask them to provide data heightens the authenticity of survey responses (Nunan, 1992).

\section{Sample}

As in Mushoriwa's (2003) study, 40 second graders (7-8year olds) and 40 fifth graders (10-11-year olds) formed the randomly selected sample for this study. The rationale for the use of these age levels was the assumption that the two age groups represent, according to Inhelder and Piaget (1964), a distinct stage in their thinking patterns, the concrete operational thought. However, it is important to note that some fifth graders will already be in the formal operational stage (See Mpofu, 1994).

\section{Instruments}

Interviews were exclusively used to collect data from respondents to avoid taking the literacy levels of the pupils for granted. The assumption was that some pupils, in the sample, if not most, might have problems comprehending a questionnaire and let alone responding to eye placements and putting justifications in writing. To further ease the data collection process, pupils were given cardboard eyes to stick on any preferred part of their bodies. This avoided the pitfalls which characterised similar studies where respondents were made to draw pictures and place the third eye. Freeman (1980) and Cox (1993) acknowledge such activities to be too challenging for children and in the investigators' opinions, even for adults who are not of an artistic nature. Such difficulties would invalidate the study's findings; hence, the attempt by the present study to make the tasks easy for the respondents. Low and Durkin's (1998) studies reveal that where children actually use their bodies, the chances of them making their placements in novel positions and making meaningful justifications for their placements increase significantly.

\section{Data collection procedures}

Interviewing was done on a one-to-one basis between the researchers and the subjects to avoid undue peer influences in the responses. The conduct of the interview was made informal and game-like to encourage free and genuine expression. The recording of the eye placements and reasons given was done without respondents' awareness. No leading questions were given and no responses were discouraged. Even non-responses were accepted and coded accordingly. The present study used the following coding system adopted from Mushoriwa (2003).

\section{Coding of eye placements}

0 - Failure/refusal to respond or to place the third eye on any part of the body.

1 - Placing the third eye between the existing/natural eyes.

2 - Placing the third eye within the face region e.g. on the forehead, between natural eyes etc.

3 - Placing the third eye anywhere else in front region of the body e.g. on the chest, stomach, etc.

4 - Placing the third eye anywhere in the back region of the body e.g. back of the head etc.

Coding of the responses for explanations/reasons

0 - Failure/refusal to explain or ambiguous explanation

1 - Attributing the placement to mass media e.g. 'I have seen it on television.'

2 - Explanation referring to natural/biological location of eyes e.g. 'This is where eyes are'

3 - Explanation relating to how frontal vision would improve if a third eye was in that location e.g. 'This would allow me to see further ahead.'

4 - Explanation focusing on how vision would be improved or more useful if one was able to see all round e.g. third eye being at the back of the head. 
The five codes used for both eye placements and explanations, were able to accommodate all the responses given. The responses were then presented and analysed as follows:

\section{Data presentation and analysis}

The coded data were key-punched for the purpose of analysis. Crosstabs and two-sample ttest were used to analyse the data. The crosstabs captured the percentage responses for eye placements and the attendant reasons. The two-sample t-test was used to test for differences, if any, in the responses by second and fifth graders. Findings from this study were then juxtaposed against those from Mushoriwa's (2003) study in Zimbabwe and emerging patterns were discussed.

Table 1 (a): Crosstab for Eye Placements for Second Graders (N=40) and Fifth Graders $(\mathrm{N}=40)$

\begin{tabular}{|l|l|l|}
\hline \multirow{2}{*}{ Eye Placements } & \multicolumn{2}{|l|}{ Respondents } \\
\cline { 2 - 3 } & $\begin{array}{l}\text { Second graders } \\
\mathbf{( 7 - 8} \text { years) }\end{array}$ & $\begin{array}{l}\text { Fifth graders } \\
\mathbf{( 1 0 - 1 1} \text { years) }\end{array}$ \\
\hline 0-Failure or refusal to respond & $2(5 \%)$ & $1(2.5 \%)$ \\
\hline 1-Placing the eye between the natural eye & $5(12.5 \%)$ & $6(15 \%)$ \\
\hline $\begin{array}{l}\text { 2-Placing the eye on the forehead or any other part within } \\
\text { the face region. }\end{array}$ & $15(37.5 \%)$ & $10(25 \%)$ \\
\hline $\begin{array}{l}\text { 3-Placing the eye anywhere else in the front region of the } \\
\text { body }\end{array}$ & $7(17.5 \%)$ & $8(20 \%)$ \\
\hline 4-Placing the eye at the back region of the body & $11(27.5 \%)$ & $15(37,5 \%)$ \\
\hline
\end{tabular}

Table 1 (a) indicates that while $5 \%$ (2) of the second graders refused or failed to respond, $2.5 \%$ (1) of the fifth graders either failed or refused to place the third eye on any part of their bodies. These pupils argued that human beings do not need three eyes at all, hence, they refused even to take the cardboard eyes from the investigators. One of the second graders commented, "Human beings were given two eyes by God, why should I need a third eye now? Take your eye and give it to those who are blind." This clearly indicates young children's inability to deal with hypothetical situations (Inhelder and Piaget, 1964).

It would appear children at this age have not yet acquired the pre-requisite cognitive skills to go beyond what exists presently; their levels of generativity are still very low, if at all they have developed. A similar study in Zimbabwe by Mushoriwa (2003) found that although all the pupils $(\mathrm{N}=80)$ placed the third eye in some parts of the body, a few were very unhappy to do that for the same reason (as in the present study) that the third eye was unnecessary for human beings.

Twelve and half percent $(12.5 \%)(5)$ of the second graders and $15 \%$ (6) of the fifth graders placed the third eye between the two natural eyes. Since generative thinking involves novelty (placing the third eye out of the usual position), the results suggest that both second and fifth graders have not fully developed generative thinking. Though the difference between second and fifth graders is very marginal in this respect (1 pupil), it is surprising that it is more of fifth graders than second graders who manifest lack of generativity. In the absence of any other reason, perhaps this observation can be explained by the fact that both groups of pupils fall within Piaget's concrete operational stage-suggesting that cognitively they are functioning at the same level.

The results in Table 1(a) also indicate that $37.5 \%(15)$ of second graders and $25 \%$ (10) of fifth graders placed the third eye on either the forehead or any other part within the face region. The difference here, as expected, favours fifth graders in terms of the extent to which they have developed generative thinking.

In the last item (item 5), $27.5 \%$ (11) of second graders and $37.5 \%$ (15) of fifth graders placed the third eye at the back region of the body-all of them placing it at the back of the head. Pupils in this category, not only portrayed novelty in their placements of the third eye, but also considered utility since they all argued that this would enable them to see all-round.

In all, these results indicate that while the majority of second graders $(37.5 \%)$ placed the third eye on the forehead or any other part within the face region, chiefly arguing that is where eyes must be, the majority of fifth graders (37.5\%) placed the third eye at the back of the head, 
basing their placement on utility. These results are consistent with findings elsewhere. For example, Mushoriwa (2003) found in Zimbabwe that $7-8^{-}$year olds showed less generative thinking than $10-11^{-}$year-olds. According to Shafer (1973), research has shown that young children either lack or have limited formal operational schemes and for us this explains the differences in the generative patterns of the two age groups.

The differences in placements of the third eye between second and fifth graders were subjected to a two-sample t-test to see whether they were significant or not. Table 1 (b) below shows the results.

Table 1 (b): Two-Sample t-Test for Eye Placements for Second $(N=40)$ Versus Fifth Graders $(N=40)$. ALPHA Level: 0.05

\begin{tabular}{|l|l|l|}
\hline & Variable 1 & Variable 2 \\
\hline Mean & 2.5 & 2.75 \\
\hline Variance & 1.384615 & 1.423077 \\
\hline Observations & 40 & 40 \\
\hline Hypothesised mean & 0 & \\
\hline Df & 78 & \\
\hline T Stat & -0.943616 & \\
\hline $\mathrm{P}(\mathrm{T}<=\mathrm{t})$ one-tail & 0.17414 & \\
\hline T Critical; one tail & 1.664625 & \\
\hline $\mathrm{P}(\mathrm{T}<=\mathrm{t})$ two tail & 0.34828 & \\
\hline T Critical; two tail & 1.990847 & \\
\hline
\end{tabular}

Since $-0.943616<1.990847$, we accept Ho and conclude that there are no significant differences in the means of second (2.5) and fifth (2.75) graders. Thus, the study did not yield any significant differences in eye placements as a function of age or grade level at the 0.05 significance level. We therefore conclude that second and fifth graders do not significantly differ in their generative thinking. These observations are consistent with findings elsewhere. For example, Ward (1994); Stokes (1999) and Mushoriwa (2003) all found that age alone is not a determinant of generative thinking. Factors such as one's I.Q. or one's home/cultural background influence the extent of generative thinking.

Table 2 (a): Crosstab of Reasons/Explanations of Second ( $N=40)$ and Fifth ( $N=40)$ Graders.

\begin{tabular}{|l|l|l|}
\hline \multirow{2}{*}{ Reason/Explanation for Eye Placement } & Respondents \\
\cline { 2 - 3 } & $\begin{array}{l}\text { Second graders } \\
\mathbf{( 7 - 8} \text { years) }\end{array}$ & $\begin{array}{l}\text { Fifth graders } \\
\text { (10-11 years) }\end{array}$ \\
\hline 0-Failure/refusal to explain or ambiguous explanation. & $7(17.5 \%)$ & $5(12.5 \%)$ \\
\hline 1-Attributing explanation to mass media. & $0(0 \%)$ & $0(0 \%)$ \\
\hline 2-Explanation referring to natural or biological location. & $9(22.5 \%)$ & $5(13.5 \%)$ \\
\hline 3. Explanation referring to improvement of frontal vision. & $10(25 \%)$ & $11(27.5 \%)$ \\
\hline 4-Explanation focusing on all-round vision & $14(35 \%)$ & $19(47.5 \%)$ \\
\hline
\end{tabular}

Seventeen and half percent (7) of second graders and $12.5 \%$ (5) of fifth graders either failed or refused to explain or give reasons for their eye placements. Some pupils in this category gave explanations such as 'I once dreamt having an eye in that position.' While no child attributed eye placement to mass media, $22.5 \%$ (9) of second graders and $12.5 \%$ (5) of fifth graders gave reasons that have to do with the biological location of human eyes. Such answers included 'So that the third eye is near the other eyes' or 'That is where eyes are found on a human being'. These children failed to think in terms of novelty (an alternative position) and utility (seeing more and better). The higher percentage of second graders $(22.5 \%)$ falling within this category seems to indicate that the development of generative thinking is age-related and therefore hierarchical in nature. Mushoriwa (2003) also arrived at similar conclusions in his study.

Twenty-five percent (10) of second graders and $27.5 \%$ (11) of the fifth graders gave reasons emphasising how frontal vision would improve if a third eye was placed in the face region. While these children have the idea of 
utility, they fail to place the third eye in a location where it would offer the greatest advantage (back of the head). On explanations/reasons focusing on all-round vision (item 5), there were $35 \%$ (14) second graders and as high as $47.5 \%$ (19) fifth graders. Reasons given included; 'So that I can see everywhere (front and back) all the time.' These pupils were concerned with how vision would be improved if one was able to see all round. This item suggests a difference in generative thinking between second graders $(35 \%)$ and fifth graders $(47.5 \%)$, with more fifth graders showing generative thinking than second graders. This result seems to be a testimony, that generative thinking is age-related.

To see whether the differences in explanations between second and fifth graders was significant or not, a two-sample t-test was carried out. The results are given in Table 2 (b).

Table 2 (b): Two-Sample t-Test for Reasons/Explanations for Second $(N=40)$ Versus Fifth $(N=40)$ Graders.

ALPHA LEVEL $=0.05$

\begin{tabular}{|l|l|l|}
\hline & Variable 1 & Variable 2 \\
\hline Mean & 2.6 & 2.975 \\
\hline Variance & 2.041026 & 1.76859 \\
\hline Observations & 40 & 40 \\
\hline Hypothesised mean difference & 0 & \\
\hline Df & 78 & \\
\hline T Stat & -1.215124 & \\
\hline $\mathrm{P}(\mathrm{T}<=\mathrm{t})$ one-tail & 0.113992 & \\
\hline $\mathrm{T}$ Critical; one tail & 1.664625 & \\
\hline $\mathrm{P}(\mathrm{T}<=\mathrm{t})$ two tail & 0.227984 & \\
\hline $\mathrm{T}$ Critical; two tail & 1.990847 & \\
\hline
\end{tabular}

Since $-1215124<1,990847$, we accept $\mathrm{Ho}$ and conclude that there are no significant differences in the reasons/explanations given by second and fifth grades for placing the third eye on the body parts they placed it on. Thus, second and fifth graders gave more or less similar reasons/explanations for placing the hypothetical third eye on the body parts they placed it on as shown by the means $(2.6$ and 2.975 respectively); though of course, fifth graders have a slightly higher mean - indicating that they were more imaginative in their placements.

Although these results contradict results obtained by Mushoriwa (2003) in Zimbabwe, one possible explanation for not finding significant differences between second and fifth graders, as argued elsewhere in this paper, is that both second and fifth graders are in Piaget's concrete operational stage. To this extent, these children tend to think and reason in the same way.

In all, the results of the present study failed to yield significant age-related differences between second and fifth graders in their generative thinking. Thus, although second and fifth graders showed slight differences in both eye placements and reasons/explanations given, these failed to reach statistical significance at 0.05 significance level. To this extent, the study tentatively concludes that second and fifth graders do not differ significantly in their generative thinking.

The present study was also interested in comparing its findings with the findings of a similar study conducted by Mushoriwa (2003) (who is one of the present writers) to see if there are differences in the results of the two studies. Although these two studies were conducted in two different environments with different samples and at different times, it was assumed that the two studies would help us see the nature and developmental pattern of generative thinking among children. The results of the two studies are juxtaposed in Tables 3(a); 3(b); 4(a) and 4(b) below. 
Table 3(a): Crosstab of Eye Placements for Second ( $N=40)$ and Fifth $(\mathrm{N}=40)$ Graders in Swaziland $(\mathrm{SW})$ Versus Eye Placements for Second $(\mathrm{N}=40)$ and Fifth $(\mathrm{N}=40)$ Graders in Zimbabwe (ZIM).

\begin{tabular}{|l|l|l|l|l|}
\hline \multirow{2}{*}{ EYE PLACEMENTS } & \multicolumn{4}{|l|}{ NUMBER OF RESPONDENTS } \\
\cline { 2 - 5 } & Second graders (7-8- years) & \multicolumn{2}{l|}{ Fifth graders (10-11-years) } \\
\cline { 2 - 5 } & SW & ZIM & SW & ZIM \\
\hline 0-Failure or refusal to respond. & $2(5 \%)$ & $0(0 \%)$ & $1(2.5 \%)$ & $0(0 \%)$ \\
\hline $\begin{array}{l}\text { 1-Placing the eye between the natural } \\
\text { eyes }\end{array}$ & $5(12.5 \%)$ & $35(87.5 \%)$ & $6(15 \%)$ & $6(15 \%)$ \\
\hline $\begin{array}{l}\text { 2-Placing the eye on the forehead or } \\
\text { any part within the face region }\end{array}$ & $15(37.5 \%)$ & $1(2.5 \%)$ & $10(25 \%)$ & $10(25 \%)$ \\
\hline $\begin{array}{l}\text { 3-Placing the eye anywhere in the } \\
\text { front facing region }\end{array}$ & $7(17.5 \%)$ & $3(7.5 \%)$ & $8(20 \%)$ & $1(2.5 \%)$ \\
\hline $\begin{array}{l}\text { 4-Placing the eye at the back region of } \\
\text { the body }\end{array}$ & $11(27.5 \%)$ & $1(2.5 \%)$ & $15(37.5 \%)$ & $23(57.5 \%)$ \\
\hline
\end{tabular}

Table 3(a) shows differences in eye placements for the Swazi and Zimbabwean samples at both second and fifth grade levels. At the second grade level, more Swazi children generally showed greater generative thinking than their Zimbabwean counterparts while at the fifth grade level, it would appear more Zimbabwean children manifested greater generative thinking than the Swazi pupils. While it was outside the scope of the present study to examine factors contributing to the differences, it should be noted that generative thinking has been found to be influenced by such factors as cultural/environmental experiences, home experiences, one's I.Q.; schooling, type of school curriculum among other things. Perhaps a study focusing on this area is urgently needed to isolate those factors that trigger and accelerate the growth and development of generative thinking in order to make our children effective thinkers.

To see whether the differences between Swazi and Zimbabwean pupils' eye placements were significant or not, a two sample t-test was conducted. The results are shown in Table 3 (b) below.

Table 3(b): Two Sample t-test for Swazi Versus Zimbabwean Children on Eye Placements.

ALPHA LEVEL $=0.05$

\begin{tabular}{|l|l|l|l|l|}
\hline & \multicolumn{2}{|l|}{ Second Grades } & \multicolumn{2}{l|}{ Fifth Grades } \\
\hline & Variable 1 & Variable 2 & Variable 1 & Variable 2 \\
\hline Mean & 2.5 & 1.25 & 2.75 & 3.025 \\
\hline Variance & 1.384615 & 0.5 & 1.423077 & 1.460897 \\
\hline Observations & 40 & 40 & 40 & 40 \\
\hline Hypothesised mean difference & 0 & & 0 & \\
\hline Df & 64 & & 78 & \\
\hline T Stat & 5.758756 & & -1.024158 & \\
\hline P (T<= t) one tail & 1.307 & & 0.154463 & \\
\hline T Critical; one tail & 1.669013 & & 1.664625 & \\
\hline P (T < t) two tail & 2.6107 & & 0.308926 & \\
\hline T Critical; two tail & 1.99773 & & 1.990847 & \\
\hline
\end{tabular}

While a significant difference $(t=5.758756>1.99773)$ in eye placements is observed between second graders in Swaziland and second graders in Zimbabwe, no significant difference $(t=1.024158<1.990847)$ in eye placements is observed between fifth graders in Swaziland and fifth graders in Zimbabwe. Mean scores $(2.5$ for Swaziland and 1.25 for Zimbabwe) indicate that for second graders, more Swazi children use greater generative thinking than Zimbabwean children. Perhaps a study focusing on reasons for such differences is needed. Fifth graders in Swaziland (mean score $=2.75$ ) and in Zimbabwe (mean score $=3.025$ ) 
show no statistically significant differences, suggesting similar levels of generative thinking among these children. The Swazi sample and
Zimbabwean sample were also compared on reasons/explanations given for eye placement preferences. Below are the results.

Table 4(a): Crosstab of Reasons/Explanations for Eye Placements for Second ( $N=40)$ and Fifth ( $N=40)$ graders in Swaziland versus Second $(\mathrm{N}=40)$ and Fifth $(\mathrm{N}=40)$ graders in Zimbabwe.

\begin{tabular}{|l|l|l|l|l|}
\hline REASON/EXPLANATION & \multicolumn{3}{l|}{ NUMBER OF RESPONDENTS } & \multicolumn{2}{l|}{ ZIM } \\
\cline { 2 - 5 } FOR EYE PLACEMENT & Second graders (7-8 years) & \multicolumn{2}{l|}{ Fifth graders (10-11 years) } \\
\cline { 2 - 5 } & SW & ZIM & $5(12.5 \%)$ & $0(0 \%)$ \\
\hline $\begin{array}{l}\text { 0-Failure/refusal to explain } \\
\text { or ambiguous explanation }\end{array}$ & $7(17.5 \%)$ & $12(30 \%)$ & $0(0 \%)$ & $0(0 \%)$ \\
\hline $\begin{array}{l}\text { 1-Attributing reason to } \\
\text { mass media }\end{array}$ & $0(0 \%)$ & $3(7.5 \%)$ & $5(12.5 \%)$ & $3(7.5 \%)$ \\
\hline $\begin{array}{l}\text { 2-Explanation referring to } \\
\text { natural or biological } \\
\text { location of the eyes }\end{array}$ & $9(22.5 \%)$ & $17(42.5 \%)$ & $14(35 \%)$ \\
\hline $\begin{array}{l}\text { 3-Explantion referring to } \\
\text { improvement of frontal } \\
\text { vision }\end{array}$ & $10(25 \%)$ & $7(17.5 \%)$ & $11(27.5 \%)$ & \\
\hline $\begin{array}{l}\text { 4-Explanation referring to } \\
\text { all-round vision }\end{array}$ & $14(35 \%)$ & $1(2.5 \%)$ & $19(47.5 \%)$ & 23 \\
\hline
\end{tabular}

Table 4(a) generally indicates relatively small differences in reasons given for eye placements between Swazi and Zimbabwean children at both Second and Fifth grade levels.
These differences were tested for significance using the two sample t-test. Table 4(b) below shows the results.

Table 4(b): Two-Sample t-Test for Swazi Versus Zimbabwean Children on Reason/Explanations for Eye Placements.

ALPHA LEVEL $=0,05$

\begin{tabular}{|l|l|l|l|l|}
\hline & \multicolumn{3}{|l|}{ Second Graders } & Fifth Graders \\
\hline & Variable 1 & Variable 2 & Variable 1 & Variable 2 \\
\hline Mean & 2.6 & 1.55 & 2.975 & 3.5 \\
\hline Variance & 2.041026 & 1.382051 & 1.76859 & 0.410256 \\
\hline Observation & 40 & 40 & 40 & 40 \\
\hline Hypothesised mean difference & 0 & & 0 & \\
\hline Df & 75 & & 56 & \\
\hline $\mathrm{t}$ Stat & 3.58931 & & -2.249448 & \\
\hline $\mathrm{P}(\mathrm{T}<=\mathrm{t})$ one tail & 0.000294 & & 0.014217 & \\
\hline $\mathrm{t}$ Critical; one tail & 1.665426 & & 1.672522 & \\
\hline $\mathrm{P}(\mathrm{T}<\mathrm{t})$ two tail & 0.000589 & & 0.028434 & \\
\hline $\mathrm{t}$ Critical; two tail & 1.992103 & & 2.003241 & \\
\hline
\end{tabular}


Table 4(b) above indicates that for both second ( $t$ $=3.58913>1.992103)$ and fifth $(\mathrm{t}=$ $2.249448>2.003241$ ) graders, there is a significant difference, at 0.05 significance level, in the reasons/explanations given for eye placements between Swazi and Zimbabwean children. While it was outside the scope of the present study to account for differences observed between Swazi and Zimbabwean children, the present writers strongly feel that researchers would be remiss if no urgent study was conducted in this area. In the writers' views, this would not only bode well for the furtherance of studies on generative thinking given its little attention in the past, but would also enhance our understanding of the nature and developmental pattern of generative thinking.

\section{CONCLUSION}

The present study set out to test the generative thinking of Swazi primary school children aged between 7 and 8 years (Grade 2) and between 10 and 11 years (Grade 5). The study went further to compare the results of the present study with those of an earlier, similar study in Zimbabwe by Mushoriwa (2003).

While the study on Swazi children failed to yield statistically significant age-related differences between second and fifth graders, generally statistically significant differences were observed between Swazi and Zimbabwean children. These results suggest that the development of generative thinking is to a considerable extent environmentally induced given that children in the same environment (Swaziland) did not manifest differences while those in different environments (Swaziland and Zimbabwe) manifested statistically significant differences. Additional research effort is needed to address these research concerns.

\section{RECOMMENDATIONS}

In the light of the research observations, the study recommends:

- $\quad$ the need for teachers to use pedagogy that promotes generative thinking, especially in lower grades. The use of novel hypothetical situations and learning that involves problem-solving have been found to promote generative thinking among children (Poole and White, 1995).

- further research in this area focusing on environmental factors that influence the nature and developmental pattern of generative thinking.

\section{REFERENCES}

Beetlestone, F.,1998. Creative Children, Imaginative Teaching. Buckingham: Open University Press.

Brookfield, S. D., 1987. Developing Critical Thinkers: Challenging Adults to Explore Alternative Ways of Thinking and Acting. Buckingham: Open University Press.

Cox, M. V., 1993. Children's Drawings of the Human Figure. Hove: Erlbaum.

De Bono, E., 1970. Lateral Thinking. New York: Harper and Row.

Freeman, N. H., 1980. Strategies of Representation in Young Children: Analysis of Special Skills and Drawing Processes. London: Academic Press.

Hamachek, D. E.,1977. Human Dynamics in Psychology and Education. Boston: Allyn and Bacon.

Harrington, D. M. 1975. Effects of explicit instructions to be creative on the psychological meaning of divergent test scores. Journal of Personality, 43, 432-454.

Inhelder, B. and Piaget, J. 1964. The Early Growth of Logic in the Child. New York: Norton.

Low, J. and Durkin, K. 1998. Structure and casual connections in children's online television narratives: What develops? Cognitive Development, 13, 201-225.

Mayer, R. E. 1989. Human nonadversary problem solving. In K. J. Guhooly (Ed) Human and Machine Problem Solving. New York: Plenum Press.

Mpofu, E. 1994. Children's interactive strategies for class inclusion tasks. British Journal of Educational Psychology, 64, 77-89. 
Mushoriwa, T. D. 2003. Generative thinking among young Zimbabwean children: A case of the third eye. Zimbabwe Journal of Educational Research, 15 (3) 173186).

Nunan, D. 1992. Research Methods in Language Learning. New York: Cambridge University Press.

Pauker, R. A. 1987. Teaching thinking and reasoning skills: Problems and solutions. AASA Critical Issues Report.

Poole, D. A. and White, L. T. 1995. Tell me again and again: Stability and change in the repeated testimonies of children and adults. In M. S. Zaragoza; J. R. Graham; G. L. N. Halt; R. Hirschman and Y. S. Ben-Porah (Eds) Meaning and Testimony in the Child Witness. London: Sage.

Shafer, D. R. 1973. Children's responses to hypothetical proposition. Unpublished manuscript, Kent State University.
Siegler, R. S. 1996. Emerging Minds: The Process of Change in Children's Thinking. New York: Oxford University Press.

Sternberg, R. J. and Davidson, J. E., 1995. The Nature of Insight. Cambridge: MIT Press.

Stokes, P. D., 1999. Learned variability levels: Implications of creativity. Creativity Research Journal, 12, 37-45.

Tidona, G., 2004. Thinking and learning. Paper presented at the Fifth International Conference on Creative Thinking, University of Malta.

Van Dalen, D. B., 1979. Understanding Educational Research: An Introduction. New York: McGraw Hill.

Ward, T. B., 1994. Structured imagination: The role of category structure in exemplar generation. Cognitive Psychology, 27, 1 -40 . 